\title{
AVALIAÇÃO DA SOLUBILIDADE DE COBRE E ZINCO EM CALDOS DE LEGUMINOSAS ${ }^{1}$
}

\author{
Édira Castello Branco de ANDRADE ${ }^{2, *}$, Aline Mota BARROS ${ }^{2}$, Iracema TAKASE ${ }^{3}$
}

\begin{abstract}
RESUMO
Os metais cobre e zinco podem se apresentar sob diversas formas químicas na natureza: como sais, estando sob a forma de íons I e II ou como compostos orgânicos, complexados com aminoácidos e proteínas. A forma mais biodisponivel ao organismo é a forma de compostos organo quelados. Avaliando os teores dos metais em caldo de leguminosas processadas termicamente em meios salino e aquoso é possivel avaliar a solubilidade destes metais. Duas marcas e dois lotes de amostras de feijão preto, feijão branco, feijão carioquinha, feijão mulatinho, feijão manteiga, ervilha e lentilha foram processadas termicamente em meios salino e aquoso e determinou-se os teores totais de cobre e zinco em seus caldos. Os caldos foram dissolvidos em $\mathrm{HCl} 2 \mathrm{molL}^{-1}$ e o teor total de cobre e zinco nas amostras foi determinado através da espectroscopia de absorção atômica em chama. Na análise da rejeição de resultados foi aplicado o teste Dixon e o teste $\mathrm{t}$ de student. Os resultados mostraram que a solubilidade média dos metais cobre e zinco nos meios aquoso e salino foram respectivamente 8 e $6 \%$. Acredita-se que os compostos de cobre e zinco nas leguminosas analisadas não são compostos inorgânicos facilmente solúveis em água. Estudos de especiação podem auxiliar na análise da biodisponibilidade destes metais.

Palavras-chave: cobre; zinco; solubilidade.
\end{abstract}

\section{SUMMARY}

EVALUATION OF THE SOLUBILITY OF COPPER AND ZINC IN A SALTY, WATRRY VEGETATABLE SOUP. Copper and zinc can appear in nature under chemical forms, such as salts, being as ions I and II or as organic compounds, synthesized as amino acids and proteins. The most bio-available form to the human body are organic compounds. The solubility of these metals can be determined by evaluating their ratio in a both of legumes thermally processed in an aqueous and a saline mediium. Samples of several varieties of beans, peas, lentils and chickpeas, in two batches containing two different brands of each variety, were thermally processeced in an aqueous and a saline medium and the total ratio of copper and zinc in their respective broths was ascertained. The broths were dissolved in HCl $2 \mathrm{molL}^{-1}$ and the total ratio of copper nad zinc in the samples was determined through atomic absorption spectroscopy on flame. Both the Dixon test and the $t$ test by Student were used in the analysis of the results rejection. The results showed that the solubility a higher ratio of copper and zinc in the broths was $7 \%$. The solubility of theses metals was not favors in the saline médium, its possible believe that these metals aren't simple inorganic compounds. Especiation studies must be applied to study their bio-availability. Keywords: copper; zinc; solubility.

\section{1 - INTRODUÇÃO}

Os minerais constituem um grupo de elementos largamente distribuídos na natureza que exercem funções diversas no organismo. O corpo humano é constituído por cerca de $99 \%$ de macronutrientes, moléculas compostas de $\mathrm{C}, \mathrm{H}, \mathrm{O}$ e $\mathrm{N}$ representadas por água, glicídios, lipídios e proteínas. Cerca de $1 \%$ do corpo de um homem adulto é composto de micronutrientes, entre esses estão os elementos traços que correspondem a quantidades menores que $0,01 \%$ da composição corporal. Os elementos traços considerados essenciais, como cobre e zinco, exercem funções relacionadas com a catálise enzimática e/ou manutenção da integridade de moléculas.[4, 7, 9, 13].

Estima-se que a "Ingestão Dietética Diária Considerada Segura e Adequada" (ESADDI - Estimate and Adequate Daily Dietary Intake) para o cobre e o zinco os respectivos valores 1,5 a $3 \mathrm{mg} /$ dia e 12 a $15 \mathrm{mg} /$ dia,

\footnotetext{
${ }^{1}$ Recebido para publicação em 13/09/1999. Aceito para publicação em 19/05/2003. (0000797)

${ }^{1}$ Universidade do Rio de Janeiro - Escola de Nutrição - Departamento de Tecnologia dos Alimentos - Av Ayrton Senna 1850 / 318 CEP 22075o0o _ Barra da Tijuca - Rio de Janeiro - RJ - Brasil - e-mail edigerah@aol.com

${ }^{2}$ Universidade Federal do Rio de Janeiro - Faculdade de Quimica - Departamento de Quimica Analitica

* A quem a correspondência deve ser enviada.
}

$[7,9]$. O processo de absorção destes metais ocorre no estômago e intestino delgado, onde a absorção máxima ocorre no intestino delgado. Esta absorção ocorre normalmente por difusão ativa, onde estes elementos se complexam a ligantes endógenos e exógenos permitindo assim seu processo de transporte e absorção [7, 9, 13, 15].

Como definição, biodisponibilidade é a fração do metal que é aproveitada pelo organismo através da absorção em relação ao teor total consumido, e está relacionada com a forma química que estes elementos se encontram nos alimentos. Os fatores que inibem a absorção do cobre e do zinco a partir do lúmen intestinal e que reduzem sua biodisponibilidade geralmente tendem a reduzir a solubilidade intraluminal ou provocar interações competitivas com processos responsáveis pelo transporte destes através da mucosa. A forma química na qual os elementos ocorrem no lúmen intestinal afeta acentuadamente sua absorção. As espécies solúveis dos metais, tais como sulfatos e nitratos, são absorvidas sem passarem por modificações químicas, enquanto outras, como carbonato, são absorvidas apenas após serem dissolvidas em secreções ácidas do estômago. Os sais solúveis, apesar de terem uma absorção favorecida em relação aos pouco solúveis e insolúveis, como óxidos e sulfetos, não são totalmente biodisponiveis. As formas solúveis do cobre são absorvidas num teor total de 40 a $60 \%$ do total ingerido; com o zinco esta absorção varia 
de 60 a $70 \%$. A existência de quelados dos elementos traço permite uma eficiência de absorção destes elementos em até $100 \%$. O conhecimento da forma química dos elementos traços é essencial para definir a biodisponibilidade dos mesmos [2, 4, 6, 8, 9, 11, 14].

O estudo da solubilidade dos metais cobre e zinco pode favorecer o conhecimento das formas que estes se encontram nos alimentos auxiliando na avaliação da biodisponibilidade destes. O presente trabalho tem como objetivo avaliar a solubilidade do cobre e do zinco em caldos de leguminosas que passaram por processamento térmico em meios aquoso e salino.

\section{2 - MATERIAIS E MÉTODOS}

\section{1 - Amostras}

Amostras de feijão preto, feijão branco, feijão carioquinha, feijão mulatinho, feijão manteiga, ervilha e lentilha, sendo duas marcas e dois lotes de cada tipo de amostra foram analisadas.

\section{2 - Tratamento das amostras}

As amostras cruas após homogeneização foram calcinadas a $550^{\circ} \mathrm{C}$ por um período mínimo de 2 horas. As cinzas foram dissolvidas em $\mathrm{HCl} 2 \mathrm{molL}^{-1}$ e transferidas quantitativamente para balão volumétrico de $25 \mathrm{~mL}$. Para a análise do caldo foram tomados $24 \mathrm{~mL}$ e o volume completado a $25 \mathrm{~mL}$ com $\mathrm{HCl} 2 \mathrm{moll}^{-1}$.

\section{3 - Processamento térmico}

As amostras foram processadas termicamente em meio aquoso e em meio salino $1 \%(\mathrm{p} / \mathrm{p})$ em relação a amostra. O sal utilizado para a cocção foi sal do tipo refinado, sendo o mesmo para todas as amostras. O processo de cocção ocorreu pelo método convencional utilizando panelas de aluminio.

\subsection{1 - Determinação do teor total de cobre e zinco}

O teor total de cobre e zinco nas amostras cruas e após processamento térmico foi determinado através da espectroscopia de absorção atômica em chama.

\subsection{2 - Tratamento estatístico}

$\mathrm{Na}$ análise da rejeição de resultados foi aplicado o teste Dixon e o teste t de Student [3].

\subsection{3 - Garantia da qualidade}

A determinação dos teores totais de cobre e zinco, foi quintuplicada. O aparelho de absorção atômica foi sempre previamente calibrado com soluções analiticas dos respectivos metais.

\section{3 - RESULTADOS E DISCUSSÃO}

O teor de cobre é mostrado na Tabela 1 para amostras cruas e nos caldos processados termicamente em meios salino e aquoso. Os resultados foram tratados estatisticamente aplicando o teste $\mathrm{t}$ de Student, intervalo de confiança 95\%, e observa-se que com exceção do feijão preto e da ervilha, que apresentaram diferença significativa dos teores de cobre nos caldos em meios salino e aquoso, em todas as outras amostras analisadas a presença deste metal nos caldos foi similar, o que pode caracterizar que o processamento térmico nos meios analisados não interfere na solubilidade do cobre, e que para os compostos de cobre, na maioria das amostras estudadas a salinidade não altera a solubilidade. DUHAN et al. [5], em estudos com ervilhas da espécie Cajanus cajan, verificaram que diferentes processamentos térmicos domésticos não promoviam perdas no conteúdo total de cálcio, fósforo e ferro.

TABELA 1. Teor percentual de cobre nas amostras de leguminosas cruas e nos caldos processados termicamente em meios salino e aquoso

\begin{tabular}{lccc}
\hline \multirow{2}{*}{ AMOSTRAS } & Cobre mg/100g amostra & \multicolumn{2}{c}{ Cobre mcg/mL caldo } \\
\cline { 2 - 4 } & Cruas & Caldo em meio salino Caldo em meio aquoso \\
\hline Feijão preto & $0,99 \pm 0,13$ & $0,48 \pm 0,13$ & $0,83 \pm 0,22$ \\
Feijão branco & $0,85 \pm 0,14$ & $0,38 \pm 0,09$ & $0,45 \pm 0,10$ \\
Feijão carioquinha & $0,69 \pm 0,09$ & $0,45 \pm 0,06$ & $0,50 \pm 0,12$ \\
Feijão mulatinho & $0,75 \pm 0,06$ & $0,33 \pm 0,1$ & $0,40 \pm 0,08$ \\
Feijão manteiga & $0,56 \pm 0,07$ & $0,20 \pm 0,08$ & $0,28 \pm 0,09$ \\
Ervilha & $0,57 \pm 0,05$ & $0,63 \pm 0,13$ & $0,85 \pm 0,24$ \\
Lentilha & $0,82 \pm 0,05$ & $0,83 \pm 0,05$ & $0,80 \pm 0,14$ \\
\hline
\end{tabular}

As amostras de feijão branco e feijão mulatinho apresentaram cerca de $5 \%$ do teor de cobre nos caldos. O feijão branco apresentou cerca de 4,5\%. O feijão carioquinha apresentou cerca de $7 \%$ e a lentilha cerca de $10 \%$. A ervilha em meio salino teve $11 \%$ do teor de cobre e em meio aquoso cerca de $15 \%$. Já para o feijão preto, os teores de cobre nos meios salino e aquoso foram respectivamente cerca de $5 \%$ e $8 \%$. Verifica-se que os teores de cobre variaram em cerca de 0,6 a $1 \mathrm{mg} /$ $100 \mathrm{~g}$ de amostra e nos caldos a variação foi de 0,02 a 0,08mg / $100 \mathrm{~mL}$ de caldo. Estudos mostram que o teor de cobre encontrado em variedades de feijões, espécies Phaseolus vulgaris e Mucuna pruriens, foi de 0,8 a $2,2 \mathrm{mg} \%$. Em cereais este mineral varia de 0,11 a $0,29 \mathrm{mg} \%[1,10,12]$.

TABELA 2. Teor percentual de zinco nas amostras de leguminosas cruas e nos caldos processados termicamente em meios salino e aquoso

\begin{tabular}{lccc}
\hline \multirow{2}{*}{ AMOSTRAS } & Zinco mg/100g amostra & \multicolumn{2}{c}{ Zinco mcg/mL caldo } \\
\cline { 2 - 4 } & $3,83 \pm 0,35$ & $2,43 \pm 0,71$ & $3,45 \pm 1,28$ \\
Feijão preto & $3,68 \pm 0,43$ & $1,43 \pm 0,21$ & $2,00 \pm 0,26$ \\
Feijão branco & $2,75 \pm 0,22$ & $1,80 \pm 0,69$ & $1,75 \pm 0,0,66$ \\
Feijão carioquinha & $2,94 \pm 0,220$ & $1,68 \pm 0,34$ & $1,90 \pm 0,42$ \\
Feijão mulatinho & $2,36 \pm 0,26$ & $2,10 \pm 0,18$ & $2,20 \pm 0,14$ \\
Feijão manteiga & $2,46 \pm 0,41$ & $2,20 \pm 0,42$ & $2,80 \pm 0,56$ \\
Ervilha & $3,22 \pm 0,81$ & $2,00 \pm 0,66$ & $2,03 \pm 0,38$ \\
Lentilha & & & \\
\hline
\end{tabular}


O teor de zinco é mostrado na Tabela 2 para amostras cruas e nos caldos processados termicamente em meio salino e aquoso. Os resultados foram tratados estatisticamente aplicando o teste t de Student, intervalo de confiança 95\%, e observa-se que com exceção do feijão branco que apresentou diferença significativa dos teores de zinco nos caldos em meios salino e aquoso, em todas as outras amostras analisadas a presença deste metal nos caldos foi similar, o que pode caracterizar que o processamento térmico nos meios analisados não interfere na solubilidade do zinco, e que para os compostos de zinco na maioria das amostras estudadas a salinidade não altera a solubilidade.

As amostras de feijão preto, feijão carioquinha e feijão mulatinho apresentaram cerca de $6 \%$ do teor de zinco nos caldos. O feijão manteiga e a ervilha cerca de $9 \%$ e a lentilha $7 \%$. Verifica-se que os teores de zinco variaram em cerca de 2,4 a 3,8mg/100g de amostra e nos caldos a variação foi de 0,14 a $0,35 \mathrm{mg} / 100 \mathrm{~mL}$ de caldo. Estudos mostram que o teor de zinco encontrado em variedades de feijões, espécies Phaseolus vulgaris e Mucuna pruriens, foi de 2,5 a 10,9mg\%. Em cereais este mineral varia de 0,65 a $2,43 \mathrm{mg} \%[1,10,12]$.

A Tabela 3 apresenta os teores percentuais de cobre e zinco dos caldo processados em meios salino e aquoso. Considerando que a solubilidade média dos metais cobre e zinco nos meios aquoso e salino foram respectivamente 8 e $6 \%$ acredita-se que os compostos de cobre e zinco nas leguminosas analisadas não são sais inorgânicos facilmente solúveis em água.

TABELA 3. Teor médio percentual em relação a amostra crua de cobre $(\mathrm{Cu})$ e zinco $(\mathrm{Zn})$ nos caldos de leguminosas processados termicamente em meios salino e aquoso

\begin{tabular}{lcccc}
\hline \multicolumn{1}{c}{ AMOSTRAS } & $\begin{array}{c}\text { \% Cu caldo em } \\
\text { meio salino }\end{array}$ & $\begin{array}{c}\text { \% Zn caldo em } \\
\text { meio salino }\end{array}$ & $\begin{array}{c}\text { \% Cu caldo em } \\
\text { meio aquoso }\end{array}$ & $\begin{array}{c}\text { \% Zn caldo em } \\
\text { meio aquoso }\end{array}$ \\
\hline Feijão preto & 4,8 & 6,3 & 8,4 & 9,0 \\
Feijão branco & 4,5 & 3,9 & 5,3 & 5,4 \\
Feijão carioquinha & 6,5 & 6,5 & 7,4 & 6,4 \\
Feijão mulatinho & 4,4 & 5,7 & 5,3 & 6,5 \\
Feijão manteiga & 3,6 & 8,9 & 5 & 9,3 \\
Ervilha & 11 & 8,9 & 14,9 & 11,4 \\
Lentilha & 10 & 6,2 & 9,8 & 6,2 \\
\hline
\end{tabular}

\section{4 - CONCLUSÕES}

A solubilidade dos compostos de cobre e zinco está relacionada com o processo de biodisponibilidade dos mesmos. Compostos solúveis apesar de terem uma absorção favorecida em relação aos pouco solúveis e insolúveis, não são totalmente biodisponíveis. Estudos de solubilidade dos compostos de cobre e zinco em caldos de leguminosas processados em meios salino e aquoso mostraram que com exceção do feijão preto e ervilha, no caso do cobre, e feijão branco no caso do zinco, as outras amostras estudadas não apresentaram diferença significativa na solubilidade nestes meios.

Em média, os teores de cobre e zinco nos caldos em meios salino e aquoso variaram respectivamente de 0,02 a 0,08mg/ $100 \mathrm{~mL}$ caldo e 0,14 a 0,35mg/100mL caldo. Considerando que a ESADDI destes metais é de no mínimo $1,5 \mathrm{mg} \mathrm{Cu}$ e $12 \mathrm{mg} \mathrm{Zn}, 200 \mathrm{~mL}$ dos caldos de leguminosas podem oferecer cerca de no mínimo $2,5 \%$ das necessidades diárias destes metais.

Considerando que a solubilidade média dos metais cobre e zinco nos meios aquoso e salino foram respectivamente 8 e $6 \%$ acredita-se que os compostos de cobre e zinco nas leguminosas analisadas não são sais inorgânicos facilmente solúveis em água. Estudos de extração e especiação podem ser favorecedores da análise da biodisponibilidade destes metais.

\section{5 - REFERÊNCIAS BIBLIOGRÁFICAS}

[1] ANDRADE, E.C.B., et al., Avaliação da biodisponibilidade de cobre e zinco em cereais crus e processados termicamente em meio aquoso e salino. Revista Brasileira de nutrição Clínica, v. 17, n. 3, p. 79-82, 2002.

[2] BARAN, J.E. Química Bioinorgãnica. Madrid: McGrall/ Interamericana de España, 1995.

[3] CHRISTIAN, G.D. Analytical Chemistry, 4a ed, USA, John Wiley \& Sons, 1986.

[4] Cozzolino, S.M.F. Biodisponibilidade de Minerais. Revista Nutrição, Campinas, p. 87-98, jul-dez 1997.

[5] DUHAN, A. et al., Effect of various domestic processing and cooking methods on phytic Acid an HClextractability of calcium, phosphorus and iron of pigeon pea, Nutrition Health v. 13, n. 3, p. 161-9, 1999.

[6] KANNAN, s. et al, Iron and zinc bioavailability in rats fed intrinsically labeled bean and bean-rice infant weaning food products, Journal of Agricultural and Food Chemistry, v. 49, n. 10, p. 5063-9, 2001.

[7] MAHAN, L. KATHELEEN, et al. Krause: Alimentos, Nutrição \& Dietoterapia, 9a ed., cap 7, São Paulo: Roca, p. 147-149, 1998.

[8] OLIVEIRA, J.M. A teoria Ortomolecular em Medicina Clínica. Rio de Janeiro, Arte Zen 2000 Prod Gráficos e Visuais, 1995.

[9] ORGANIZAÇÃO MUNDIAL DE SAÚdE; Elementos Traço na Nutrição e Saúde, cap.7, São Paulo: Roca, p. 108-122, 1998.

[10] SAMMAN, N. et al., Composition of different bean varieties (Phaseolus vulgaris) of Northwestern Argentina (Region NOA) : cultivation zone influence. Journal fo Agricultural anf Food Chemistry, v. 47, n. 7, p. 2685-9, 1999.

[11] SANDSTROM, BRITTMARIE et al; Effect of protein level and Protein Source on Zinc Absorption in Humans. The Journal of Nutrition, v. 119, n. 1, p. 48-52, 1989.

[12] VADIVEL, V.; JANARDHANAN, K. Nutritional and antinutritional composition of velvet bean:an underutilized food legume in south India. International Journal of Food Science an Nutritional v. 51 , n. 4, p. 279-87, 2000.

[13] WAITZBERG, D.L. Nutrição Oral, Enteral e Parenteral na Prática Clínica. $3^{\mathrm{a}}$ ed. São Paulo:Editora Atheneu, p. 131-134, 2002.

[14] WANG, J. et al, A primary study on chemical bound forms of copper and zinc in wheat and rape, Ying Yong Sheng Tai Xue Bao, v. 4, n. 11, p. 629-30, 2000.

[15] WAPNIR, RAUL a et al; Intestinal Absorption of Copper: Effect of Sodium. Proceeding of the Society for Experimental Biology and Medicine, v. 185, n. 3, p. 277-282, 1987. 